\title{
G. Edward Schuh: o professor-amigo que valorizou para sempre a agricultura brasileira
}

Paulo Fernando Cidade de Araújo

Em 4 de maio de 2008, perdemos um grande professor e amigo do Brasil e da SOBER. G. Edward Schuh não foi apenas um grande homem e bom amigo. Mais do que isso, foi o mestre que mudou a economia agrícola para sempre, valorizando-a no contexto macroeconômico. E como bem disse o Professor Terry Roe, da University of Minnesota, ele fez uma enorme diferença em todas as dimensões da vida.

Ed Schuh - como gostava de ser chamado - nasceu em Indianápolis, Estado de Indiana nos Estados Unidos, aos 13 de setembro de 1930. Filho de agricultor cresceu e aprendeu a conhecer a vida e os problemas da agricultura no meio rural. Casado com Maria Ignez, brasileira de Piracicaba, SP, deixa três filhas - Audrey, Susan e Tanya - e três netos. Foi o pai-amigo de uma grande família, incluindo estudantes de muitos países.

Formou-se em Agricultural Education na Purdue University em 1952. Obteve o título de Master of Science em Agricultural Economics na Michigan State University em 1954. Após dois anos servindo ao Exército Americano na Coréia do Sul e no Japão, ingressou na University of Chicago em 1956, onde obteve os títulos de Master of Arts em 1958 e de Ph.D em 1961.

Na Purdue University, realizou brilhante carreira de professor entre 1961 e 1979. Atraiu para Lafayette um bom número de brasileiros para 
realizar programas de Ph.D em economia rural. Eliseu Alves, Antonio Salazar Pessoa Brandão, Alberto Veiga, Mauro Lopes, Ignez Lopes, José Ramalho, Andrés Villas, Túlio Barbosa, Teotônio Teixeira, Antonio Jorge de Oliveira e Guilherme Dias (em pesquisa sobre agricultura de baixa renda) são bons exemplos de uma sólida convivência acadêmica com o professor-amigo Ed Schuh.

Ademais, serviu como Consultor da Fundação Ford entre 1966 e 1972 e como Subsecretário dos Programas Internacionais de Negócios e Commodities, no Departamento de Agricultura dos Estados Unidos em Washington D.C., no biênio 1978-79.

Também em 1979, iniciou outra etapa de sua vida acadêmica na chefia do Departamento de Economia Aplicada da University of Minessota. Entre 1984 e 1987, foi diretor do Departamento de Agricultura e Desenvolvimento Rural do Banco Mundial, em Washington D. C. Em seguida, retorna à University of Minnesota, como Dean do Humphrey Institute of Public Affairs (1987-1997) e, depois, como coordenador de International Fellowship Programs desse Instituto (1997-2003).

Tal com acontecera na Purdue University, outros brasileiros - como Geraldo Calegar, Carlos Santana, Ana Lucia Kassouf, Afonso Negri Neto, Geraldo de Camargo Barros e o próprio Salazar Brandão - realizaram seus programas de Ph.D, de pós-doutorado ou de professor visitante na University of Minnesota.

Em sua aposentadoria foi homenageado, em maio de 2007, com a realização do chamado Schuh Symposium sobre o tema “TOWARD $\boldsymbol{A}$ GLOBAL FOOD AND AGRICULTURAL FOR ANOPEN INTERNATIONAL ECONOMY" em Minneapolis. Logo em seguida continuou ensinando e pesquisando com o entusiasmo de sempre.

Na academia, vale dizer - de vários países do mundo, orientou pelo menos 150 dissertações e teses de mestrado e doutorado. Desse total, 40 foram sobre problemas brasileiros. Foi autor de seis livros e editor/co-editor de outros tantos. Escreveu dezenas de capítulos de livros e publicou mais de cem artigos técnicos e científicos.

Em quase uma centena de países, G. Edward Schuh contribuiu como educador, administrador, conselheiro, consultor e autor nas áreas de economia e agricultura, com particular interesse em questões de política agrícola, política de segurança alimentar, desenvolvimento 
econômico, comércio internacional e política cambial, capital humano e desenvolvimento tecnológico. Realizou intensivo trabalho viajando mundo afora. Mas sempre que podia passava pelo Brasil, na sua querida Viçosa em Minas Gerais e na familiar e também querida Piracicaba em São Paulo.

Nos Estados Unidos, recebeu cinco prêmios profissionais da American Association of Agricultural Economics: - melhor tese de PhD, em 1961; - melhor pesquisa publicada, em 1971; melhor artigo publicado, em 1974; contribuição relevante para análise de política econômica, em 1979; e, publicação de valor permanente, em 1979. Entre as honrarias e distinções de mérito acadêmico destacam-se: Doutor em Agricultura, Honoris Causa, da Purdue University (1992). Membro (eleito) em 1977 da American Academy of Arts and Sciences e, em 1988, Regent Professor Emeritus, a mais alta honraria acadêmica da University of Minnesota.

Ed Schuh participou de vários conselhos. Presidiu o Board for International Food and Agricultural Development. Foi também presidente do University of Minnesota Rural Development Council e integrou - como membro - o Board of Trustees do International Food Policy Research Institute. Ademais, foi membro do Council of Economic Advisors do Presidente Gerald Ford.

Envolveu-se ativa e positivamente em projetos de organizações nacionais e internacionais. Apenas para exemplificar, junto ao United States Food Security Advisory Committee, ao Board on Agriculture and Natural Resources, ao Carter Center, à Sasakawa Africa Association e ao Thailand-Minnesota Program. Referência especial merece o projeto que realizou em parceria com Antonio Salazar Brandão em 1992. A convite de Lee Martin e da American Agricultural Economics Association, escreveu e publicou The Theory, Empirical Evidence, and Debates on Agricultural Development Issues in Latin America: Selected Survey.

Com certeza, o Brasil constituiu capítulo especial na vida de Ed Schuh. Desde que aqui chegou, aprendeu a admirar a cultura e o povo brasileiro e a valorizar a importância da agricultura no processo de desenvolvimento do país. Tanto ele acreditou em nossa agricultura 
que adquiriu e administrou uma fazenda na região centro-oeste, em Mato Grosso do Sul, onde se realiza até hoje profunda transformação tecnológica. Suas idéias sobre o retorno social à pesquisa e à extensão na agricultura, sobre a capacidade do País gerar excedentes para o pleno desenvolvimento, sobre a necessidade de se priorizar o papel da política cambial visando maior exposição ao comércio internacional, bem como sobre a validade e urgência de políticas macroeconômicas em favor dos pobres - por exemplo, são apenas apreciáveis parcelas de seu legado. E tudo isso começou na Universidade Federal de Viçosa em Minas Gerais, instituição pioneira na pós-graduação no Brasil, onde Ed ajudou a implementar, com a equipe do acordo entre a Purdue University e a UFV, sólido e bem sucedido programa de pós-graduação em economia rural. Foi aí que conheceu Ignez, sua mulher e companheira de quarenta e três anos.

Entre 1963 e 1965, permaneceu como professor visitante da Universidade Federal de Viçosa, onde contribuiu como mestre-amigo de um bom número da primeira geração de professores e especialistas brasileiros. Lembro-me bem de Helio Tollini, Túlio Barbosa, Antonio Raphael Teixeira Filho, Eliseu Alves, José Ramalho, Fernando Rocha, Euter Paniago, Hilton Cunha e tantos outros. Da UFV recebeu o honroso título de Doutor Honoris Causa em 1965.

Na sua passagem pela Fundação Ford, na cidade do Rio de Janeiro - contribuiu para o desenvolvimento de várias instituições brasileiras de ensino e pesquisa, apoiando o financiamento de projetos importantes e a concessão de bolsas de estudo de Ph.D no exterior. Este foi o caso da UFV, da ESALQ/USP, do IEA, da FEA-FIPE/USP, do CEBRAP e do IPEA.

Em Piracicaba, na Escola Superior de Agricultura Luiz de Queiroz foi professor e pesquisador em vários momentos: 1975, 1977, 1999 a 2002 e 2007. Por proposta do Centro de Estudos Avançados em Economia Aplicada (CEPEA) e do Departamento de Economia, Administração e Sociologia da ESALQ, a Congregação da ESALQ aprovou, em 2005, o seu nome como professor visitante - na mais alta titulação docente, o que infelizmente não chegou a se concretizar. Além disso, recebeu singela homenagem dos professores de economia da ESALQ, ao ter o seu nome atribuído a uma das salas de aula de Programa de Pós-Graduação. Era na sala de aula que Ed Schuh se sentia mais a vontade. 
Colaborou em vários momentos com um grande número de instituições brasileiras. Foi consultor junto ao Ministério da Agricultura (1974), ao Instituto de Pesquisas Tecnológicas (1979), à Empresa Brasileira de Pesquisa Agropecuária (1980-83, e em outros momentos especiais). Foi também Membro dos Conselhos Editoriais da Revista Brasileira de Economia e Sociologia Rural e da Fundação de Estudos Agrários Luiz de Queiroz.

Contribuiu com a Sociedade Brasileira de Economia e Sociologia Rural desde que chegou ao Brasil em 1963. Participou de muitos Congressos, proferiu aulas magnas, produziu e publicou artigos, deu pareceres para a nossa Revista. Além disso, tomou a iniciativa de propor a criação de a Sociedade premiar - anualmente - o autor da melhor dissertação de Mestrado de economia agrícola. Prêmio que recebeu o seu nome. Pelo muito que fez, foi eleito Membro Legendário da SOBER, em 2004. Um ano depois, em 2005, do Presidente da República do Brasil, mereceu a Grã-Cruz da Ordem Nacional do Mérito Científico, do Ministério da Ciência e Tecnologia.

Em São Paulo, foi marcante a presença intelectual de Ed Schuh. Sua ligação profissional com o Instituto de Economia Agrícola começou no final da década de 1960, quando Rubens Araújo Dias dirigia o Instituto. Participou da elaboração do chamado Livro vermelho do IEA - Desenvolvimento da Agricultura Paulista (1970). Em 1973, colaborou com a Comissão Organizadora Local da International Conference of Agricultural Economists promovida pela International Association of Agricultural Economists (IAAE). Na Conferência de 1973, Schuh integrou a equipe que apresentou as características econômicas e os problemas da agricultura brasileira e paulista. Em 1974, participou do Seminário Internacional sobre Custos de Produção na Agricultura, inclusive apresentando trabalho sobre a teoria dos custos. E até 1977 - como Consultor Ad Hoc - colaborou em vários projetos de pesquisa do IEA. Some-se a esses momentos, sua participação destacada no Seminário Internacional de Política Agrícola (1988). 


\section{II}

Nesses 44 anos de parceria em ensino e pesquisa, só aumentou a minha admiração pelo professor-amigo G. Edward Schuh. Destaco inicialmente a dedicação e o cuidado com que preparava todas as aulas. Em suas paginas amarelas, preparava - com luxo de detalhes - até mesmo os assuntos mais simples. E sempre com o cuidado de apresentar os fundamentos teóricos e as possíveis implicações práticas e empíricas. Tive a oportunidade de dividir com ele as aulas da disciplina Desenvolvimento Econômico e a organização de uma coletânea de quatro livros sobre Desenvolvimento da Agricultura. As suas notas de aula até hoje me parecem atuais, especialmente no caso das economias em desenvolvimento. Com elas, aprendi a valorizar o papel da agricultura num contexto macroeconômico de desequilíbrios e desencontros. Percebi quão essencial para o desenvolvimento econômico é a geração de excedente físico, comercial e financeiro na agricultura, como William Nicholls havia mostrado teoricamente. Entendi como funcionam as relações (autônomas e interdependentes) entre os mercados de produto e de fatores de produção, colocando sempre em primeiro plano a discussão sobre as formas de organizar a produção e o sistema de pesquisa, como T.W.Schultz havia proposto. Passei a valorizar mais os efeitos indiretos das políticas macroeconômicas sobre a agricultura do que os efeitos diretos de muitas políticas agrícolas ou de industrialização com esquema forçado, como sugerido por Ed Schuh em seu paper "Efeitos de Políticas Gerais de Desenvolvimento Econômico no Desenvolvimento Agrícola" ${ }^{1}$. E nesse sentido, o que dizer da capacidade de alimentar os pobres e da necessidade de um crescimento mais balanceado em relação à esperança de auto-sustentação?

Outra lição importante está no seu clássico e permanente artigo "The exchange rate and U.S. agriculture”. Com efeito, ele define a agricultura como parte de um sistema global de produção de alimentos que enfatiza o papel da taxa de câmbio e de outros fenômenos monetários que

1 Publicado no American Journal of Agricultural Economics (AJAE, Vol.50, no.5, 1968, p.1283-1293). 
influenciam preços, exportações e produção². A experiência brasileira, a partir da mudança de política cambial em janeiro de 1999, mostra a solidez das idéias de Ed Schuh. Ademais, robustece os argumentos em favor do comércio internacional para agricultura brasileira como fonte de crescimento econômico.

Finalizando esta mensagem, vale a pena lembrar - como lição para o futuro - a preocupação de Schuh com a modernização do setor de alimentos para o aumento da renda dos pobres e desamparados. Em nosso último trabalho de pesquisa, em boa hora, nos chamou atenção para a necessidade de a FAPESP desenvolver programas estratégicos para modernizar a produção de alimentos na agricultura familiar de baixa renda. Este tipo de preocupação esteve sempre presente na mente de Ed Schuh.

\section{Publicações selecionadas}

G. EDWARD SCHUH. 1962. An econometric investigation of the market for hired labor in agriculture. The Journal of Farm Economics, vol. 44, no. 2, p.307-321.os

G. EDWARD SCHUH and ALVES, ELISEU. 1970. The Agricultural Development of Brazil., New York:Frederick A. Praeger, Inc.

G. EDWARD SCHUH. 1974. The exchange rate and U.S. agriculture. American Journal of Agricultural Economics, vol. 56, no. 1, p. 1-13.

G. EDWARD SCHUH and BRANDÃO, A. S. P. 1979. Terms of trade and economic welfare: some qualitative propositions. Revista Brasileira de Economia, vol. 33, no. 1, p. 3-24.

G. EDWARD SCHUH. 1986. The United States and the Developing Countries: An Economic Perspective., The National Planning Association.

G. EDWARD SCHUH and BRANDÃO, A. S. P. The Theory, Empirical Evidence, and Debates on Agricultural Development Issues in Latin America: Selected Survey. In: LEE R. MARTIN (Editor). 1992. A Sur-

2 Nas palavras de C. Ford Runge, professor de Economia Aplicada e Direito da University of Minnesota. 
vey of Agricultural Economics Literature: Vol. 4 - Agricultural Economic Development from 1940’s to 1990's. American Agricultural Economics Association (A.A.E.A.).

G. EDWARD SCHUH. 1999. Agriculture and economic development. The Chicago Policy Review, vol. 3, p. 7-65. Special Edition.

ARAUJO, PAULO F. CIDADE DE, G. EDWARD SCHUH, ALEXANDRE MENDONÇA DE BARROS, RICARDO SHIROTA and ALEXANDRE CHIBEBE NICOLELLA. 2004. O Crescimento da Agricultura de São Paulo e as Instituições de Ensino, Pesquisa e Extensão: Uma Perspectiva a Longo Prazo., São Paulo:FAPESP. 